\title{
Research on Job Satisfaction and Influencing Factors of Scientific Researchers in S Hospital of Guizhou Province
}

\section{Shanyong Fu}

Guizhou University https://orcid.org/0000-0002-1649-1030

\section{Yujie Nie}

Guizhou Provincial People's Hospital

Hui Chen (D676626648@qq.com)

Guizhou Provincial People's Hospital https://orcid.org/0000-0001-9075-9130

Yingjie Nie

Guizhou Provincial People's Hospital

\section{Research}

Keywords: Hospital, Scientific research personnel, Job satisfaction, Influencing factors

Posted Date: January 25th, 2021

DOI: https://doi.org/10.21203/rs.3.rs-153209/v1

License: (a) (i) This work is licensed under a Creative Commons Attribution 4.0 International License. Read Full License 


\section{Abstract}

Objective: To analyze the job satisfaction of hospital researchers and its influencing factors.

Methods: A questionnaire survey was conducted to investigate the job satisfaction of 276 researchers in $S$ Hospital of Guizhou Province from May to July of 2020. Independent sample $T$ test and one-way variance were used to analyze the satisfaction of researchers with demographic characteristics. Multiple linear regression analysis was used to analyze the factors affecting the satisfaction of researchers.

Results: The average score of the hospital researchers' overall job satisfaction was $3.64 \pm 0.42$, which was at the satisfaction level. The six dimensions, including self-efficacy, scientific research system and salary and welfare, were significantly positively correlated with overall satisfaction $(r 0.4)$. The differences in overall satisfaction of different ages were statistically significant $(P=0.013<0.05)$. The linear regression analysis found that all the six dimensions had a significant positive impact on the overall job satisfaction, of which the scientific research system had the most significant impact.

Conclusion: We can improve the hospital scientific research level by improving the salary and welfare level of scientific research staff, changing the scientific research management concept, establishing and perfecting the scientific research management system, and taking targeted measures for the researchers with low satisfaction.

\section{Introduction}

The level of hospital scientific research affects the comprehensive strength of the hospital, represents the competitiveness of the hospital in the medical field, and also determines the innovation ability of the hospital. With the competition of large-scale public hospitals gradually turning from extensive scale expansion to fine management and key discipline construction, the scientific research construction and management in "medical technology, science, education and research" also become important support for "key disciplines, superior talents, resource aggregation and achievement transformation"[1]. Therefore, it is highly concerned by hospital leaders and research managers to create a good scientific research atmosphere, stimulate the enthusiasm of medical staff for scientific research and promote the better development of scientific research. In practical work, Hospital researchers have a special dual identity. They are not only the main body of medical work, but also the main body of scientific research. They should not only deal with the busy business work, deal with the complex doctor-patient relationship, but also complete the very important scientific research tasks[2-3]. Especially in large general hospitals, scientific research achievements are closely related to the promotion of professional titles[4]. Multiple pressure has become the main contradiction that affects hospital researchers to engage in scientific research. Therefore, it is necessary to measure the satisfaction of hospital researchers so as to have a timely and in-depth understanding of the working conditions of hospital researchers.

According to the current scholars of the existing research results, the researchers satisfaction influenced by many factors, such as JiWeiPing, PuJiang etc. [2] in the hospital scientific research management 
based on the employee satisfaction survey in the study found that men and women hospital scientific research personnel's job satisfaction in the gender group there was no statistically significant difference when comparing satisfaction score, and in the medical sequence and auxiliary departments, junior, middle and senior titles satisfaction to compare the difference was statistically significant. Zhang Yingyuan, Chen Zhuo et al.[5] conducted a research satisfaction survey on the professional and technical personnel of Beijing Maternity Hospital, so as to understand and analyze the differences in the scientific research satisfaction of different types of professional and technical personnel and explore the factors affecting the satisfaction. The results show that the researchers' satisfaction with the research of the institute is between "relatively satisfied" and "average", and it is also found that the research satisfaction is influenced by both subjective feelings and objective environment. Zhang Huifang, Miao Miao et al. [6] conducted a survey on the satisfaction of scientific researchers in a tertiary hospital from the perspective of scientific research incentive. It was found that in terms of the degree of respect is lower, the higher the degree of staff satisfaction in scientific research, transformation and scientific researchers' awareness to protect the satisfaction of the minimum senior titles, and in terms of different job categories, engaged in clinical and basic researchers research the lowest satisfaction. Through literature review, it is found that at present, most studies on the job satisfaction of hospital staff are done by clinical workers or nursing staff, and there is a lack of attention to hospital researchers. Therefore, this paper takes the hospital scientific research personnel as the research object, carries out the job satisfaction survey, and discusses the influencing factors of the group satisfaction, so as to provide the practical basis for the leaders to think about how to improve the satisfaction of the scientific research personnel and stimulate the scientific research vitality of the medical staff, and also provides a reference for the hospital to formulate more reasonable and applicable policies and stimulate the enthusiasm of medical staff in scientific research.

\section{Objects And Methods}

\subsection{Objects}

The inclusion criteria of the respondents are as follows: first, presiding over or participating in scientific research projects as a main member of the project team; Second, he has published more than one research paper in Chinese science and technology core journals or above. Third, all the respondents are formal staff of the hospital[2]. A questionnaire survey was conducted to investigate the job satisfaction of researchers in S Hospital of Guizhou Province who met the above three standards. A total of 276 questionnaires were collected in this survey, 39 of which were invalid and 237 of which were valid, with an effective recovery rate of $86 \%$.

\subsection{Methods}

\section{Questionnaire setup}

Satisfaction is the psychological and physiological feeling of employees [7],with strong subjectivity. Besides, the cognition of different individuals will be affected by individual experience, self-interest and 
other factors, so it is necessary to study from different angles and using various ways and methods [810].Therefore, the Spector job satisfaction survey scale [11] was used in this study to design a questionnaire for medical staff's scientific research satisfaction in combination with relevant domestic scales[12].The survey included basic information (gender, age, education level, etc.) of the hospital researchers. Job satisfaction, this part is divided into two scales: the job itself and the working relationship, which contain 26 indicators. In the part of job satisfaction, a five-point likert scale was used. The answers were set as "very disagree", "disagree", "general", "agree" and "very agree", and the scores were recorded as 1-5 points in turn. The average satisfaction of 1-2 points is defined as "dissatisfaction", 2-3 points is defined as "general", 3-4 points is defined as "satisfied", 4-5 points is defined as "very satisfied".

\section{Quality Control}

In order to ensure the scientificity and effectiveness of the research, the research group did a pre survey on the questionnaire, and tested its reliability and validity. After several revisions, the final version was confirmed. In order to ensure the quality of data, the parallel double entry method was adopted to enter all data information and establish a database. The reliability test results of the formal questionnaire showed that the Cronbachs' coefficients[13] of the total questionnaire and the two subscales were both greater than 0.8 , indicating that the questionnaire had strong reliability. Exploratory factor analysis was used to detect the validity of the scale. The analysis results showed that the KMO value of the scale was 0.881 ,

and the Bartlett spherical test $c^{2}$ was 3352.990. The corresponding significance level was $P<0.001$, which was suitable for factor analysis and also indicated that the validity of the questionnaire was relatively high.

\subsection{Statistical methods}

EPiData3.1 was used to establish a database, and after data cleaning, SPSS24.0 was used for statistical analysis. Measurement data are expressed as $\overline{\mathrm{x}} \pm \mathrm{s}$. Independent sample $\mathrm{T}$ test and one-way variance were used to analyze the satisfaction difference of researchers with different demographic characteristics. Multiple linear regression was used to analyze the factors affecting the satisfaction of hospital researchers, and the difference of $P<0.05$ was statistically significant.

\section{Results}

\subsection{Sample description}

A total of 237 valid questionnaires were collected, and the effective recovery rate was $86 \%$. Among the 237 researchers, 95 were male (40.1\%), 142 were female (59.9\%); the respondents were 30-39 years old, accounting for $57.0 \% ; 87.8 \%$ of the respondents were married; $57.4 \%$ of the respondents had master's degree; $90.3 \%$ had master's degree and doctor's degree; $30.4 \%$ had worked for $6-10$ years; $40.9 \%$ of the respondents had intermediate professional titles; the respondents were scientific researchers $60.3 \%$ of the posts were clinicians, as shown in Table 1. 
Table 1

Demographic characteristics of hospital researchers

\begin{tabular}{|c|c|c|c|}
\hline Characteristics & Variable & $\mathbf{n}$ & $\%$ \\
\hline \multirow[t]{2}{*}{ Gender } & Male & 95 & 40.1 \\
\hline & Female & 142 & 59.9 \\
\hline \multirow[t]{4}{*}{ Age } & 29 years and under & 31 & 13.1 \\
\hline & $30-39$ years & 135 & 57.0 \\
\hline & $40-49$ years & 61 & 25.7 \\
\hline & 50 years and above & 10 & 4.2 \\
\hline \multirow[t]{2}{*}{ Marital status } & Unmarried & 29 & 12.2 \\
\hline & Married & 208 & 87.8 \\
\hline \multirow[t]{3}{*}{ Education } & undergraduate & 23 & 9.7 \\
\hline & master & 136 & 57.4 \\
\hline & Doctor and above & 78 & 32.9 \\
\hline \multirow[t]{4}{*}{ Working years } & $1-5$ years & 60 & 25.3 \\
\hline & $6-10$ years & 72 & 30.4 \\
\hline & $11-15$ years & 45 & 19.0 \\
\hline & More than 16 years & 60 & 25.3 \\
\hline \multirow[t]{4}{*}{ Title } & Junior and below & 48 & 20.3 \\
\hline & intermediate & 97 & 40.9 \\
\hline & Deputy senior title & 62 & 26.2 \\
\hline & Senior title & 30 & 12.7 \\
\hline \multirow[t]{6}{*}{ Job category } & clinical & 143 & 60.3 \\
\hline & Medical technology & 50 & 21.1 \\
\hline & administration & 9 & 3.8 \\
\hline & nursing & 31 & 13.1 \\
\hline & basics & 2 & 0.8 \\
\hline & others & 2 & 0.8 \\
\hline
\end{tabular}


The principal component extraction method and the maximum variance method were used for orthogonal rotation, and the common factor was extracted with the principle of eigenvalue greater than 1[14]. Four components were extracted from the "Work itself" scale and two from the "working relationship" scale. The variance interpretation rates of each component in the two large tables were $14.998 \%, 12.033 \%, 10.198 \%, 9.837 \%, 9.499 \%$ and $7.913 \%$, respectively. The cumulative variance contribution rate of the six components was $64.477 \%$. By referring to relevant literature and the meaning reflected by each item in each component, the scale of "work itself" was divided into four dimensions: scientific research system, scientific research management, self-efficacy, salary and welfare, and the scale of "working relationship" was divided into two dimensions: leadership factor and colleague relationship[15].

\subsection{Descriptive statistics}

The analysis results showed that the average score of overall satisfaction of hospital researchers was $3.64 \pm 0.42$, which was at the satisfaction level. The average scores of the other six dimensions, from high to low, were self-efficacy, scientific research management, scientific research system, colleague relationship, leadership factors, and salary and welfare, as shown in Table 2.Pearson correlation analysis was used to study the correlation between each dimension of researchers' satisfaction and the overall satisfaction, and the results showed that the correlation coefficient " $r$ " between each dimension and the overall satisfaction was greater than 0.4 ,indicating that there was a significant positive correlation between each dimension and the overall satisfaction $(P<0.001)$, and each dimension has a certain influence on the overall satisfaction effect, with the scholar S Kim, SM Park claims (employees' job satisfaction were the major influencing factors of the job itself,boss, pay,promotion,working environment and colleague) similar[16].

Table 2

satisfaction of researchers in different dimensions

\begin{tabular}{|llll|}
\hline Dimension & $\begin{array}{l}\text { Mean } \\
(\overline{\mathbf{x}} \pm \mathbf{s})\end{array}$ & $\boldsymbol{P}$ & \\
\hline self-efficacy & $3.85 \pm 0.66$ & 0.677 & $<0.001$ \\
\hline scientific research system & $3.70 \pm 0.68$ & 0.792 & $<0.001$ \\
\hline scientific research management & $3.83 \pm 0.56$ & 0.819 & $<0.001$ \\
\hline salary and welfare & $3.42 \pm 0.57$ & 0.602 & $<0.001$ \\
\hline leadership factors & $3.45 \pm 0.58$ & 0.485 & $<0.001$ \\
\hline colleague relationship & $3.66 \pm 0.51$ & 0.745 & $<0.001$ \\
\hline
\end{tabular}

\subsection{Difference analysis}


The results showed that the mean values of male and female satisfaction on the dimension of leadership factors were 3.35 and 3.51 , respectively, $t=-2.13$ and $P=0.034$. The mean satisfaction with leadership factors of researchers with bachelors, masters and doctors were $3.89,3.51$ and 3.21 , respectively, $F=$ 15.660 and $P=0.000$. The mean satisfaction with leadership factors of researchers with Junior and below titles, intermediate titles, deputy senior titles and senior titles were 3.62, 3.46, 3.40 and 3.23, respectively, $F=3.120$ and $P=0.027$. It shows that the difference of gender, educational background and professional title has statistical significance to the leadership factors.

The results of one-way ANOVA showed that the mean satisfaction of researchers aged 29 and below, 30$39,40-49,50$ and above were $3.76,3.76,4.00$ and 3.84 respectively, $F=2.889, P=0.036$. According to the above age groups, the mean of the overall satisfaction of researchers is $3.64,3.58,3.79$ and 3.57 , respectively. In terms of overall satisfaction, $F=3.662, P=0.013$, which shows that there are significant differences between different ages in terms of scientific research management and overall satisfaction.

The results of one-way ANOVA for different ages, education, working years, professional titles and job categories also showed that these demographic variables had statistically significant differences in salary and welfare $(P<0.05)$. Specifically, there were significant differences in the satisfaction of researchers at different ages. The satisfaction of researchers aged 40-49 was the highest, followed by those aged over 50 years old, and the lowest among those under 29 years old and 30-39 years old;The job satisfaction of researchers with different educational backgrounds: the lower the educational background, the lower the satisfaction; The job satisfaction of researchers with different working years: those with 6-10 years of working life were the least satisfied, and the satisfaction increased after 11 years of working life. The job satisfaction of researchers with different professional titles: the satisfaction of researchers with intermediate professional titles was the lowest, and the higher the professional titles were from then on, the higher the satisfaction was. The satisfaction of researchers of different job categories: the satisfaction of researchers in administrative posts is the highest, followed by clinical posts, and the satisfaction of researchers in basic posts is the lowest. See Table 3 for details. 
Table 3

A one-way ANOVA for researchers' satisfaction with salary and welfare

\begin{tabular}{|c|c|c|c|c|}
\hline $\begin{array}{l}\text { Influencing } \\
\text { factors }\end{array}$ & Variable & $\begin{array}{l}\text { Mean } \\
(\overline{\mathbf{x}} \pm s)\end{array}$ & $F$ & $P$ \\
\hline \multirow[t]{4}{*}{ Age } & 29 years and under & $3.27 \pm 0.34$ & 19.264 & 0.000 \\
\hline & $30-39$ years & $3.26 \pm 0.53$ & & \\
\hline & $40-49$ years & $3.84 \pm 0.55$ & & \\
\hline & 50 years and above & $3.55 \pm 0.40$ & & \\
\hline \multirow[t]{3}{*}{ Education } & undergraduate & $3.28 \pm 0.37$ & 5.595 & 0.004 \\
\hline & master & $3.35 \pm 0.53$ & & \\
\hline & Doctor and above & $3.60 \pm 0.65$ & & \\
\hline \multirow[t]{4}{*}{ Working years } & $1-5$ years & $3.24 \pm 0.41$ & 23.848 & 0.000 \\
\hline & $6-10$ years & $3.17 \pm 0.53$ & & \\
\hline & $11-15$ years & $3.49 \pm 0.48$ & & \\
\hline & More than 16 years & $3.85 \pm 0.57$ & & \\
\hline \multirow[t]{4}{*}{ Title } & Junior and below & $3.27 \pm 0.34$ & 23.117 & 0.000 \\
\hline & intermediate & $3.19 \pm 0.45$ & & \\
\hline & Deputy senior title & $3.66 \pm 0.67$ & & \\
\hline & Senior title & $3.93 \pm 0.48$ & & \\
\hline \multirow[t]{6}{*}{ Job category } & clinical & $3.51 \pm 0.60$ & 2.326 & 0.044 \\
\hline & Medical technology & $3.31 \pm 0.51$ & & \\
\hline & administration & $3.53 \pm 0.32$ & & \\
\hline & nursing & $3.22 \pm 0.51$ & & \\
\hline & basics & $2.88 \pm 0.18$ & & \\
\hline & others & $3.38 \pm 0.88$ & & \\
\hline
\end{tabular}

\subsection{Multiple linear regression analysis}

For the further study of scientific research personnel's overall job satisfaction of each dimension, ruled out the mixed interference of the age, with self-efficacy (X1), the scientific research management (X2), scientific research system (X3), salary welfare (X4), leading factors (X5) and colleague factors (X6) were 
taken as independent variables, with the average scores of the overall satisfaction $(Y)$ as the dependent variable linear regression analysis. Results showed that six dimensions were significantly positive influence on overall satisfaction (beta $>0, P<0.05$ ), the influence degree of each dimension for the overall satisfaction from high to low in turn is the scientific research system (beta $=0.283$ ), the scientific research management (beta $=0.272$ ), and self-efficacy (beta $=0.244$ ), leading factor (beta $=0.223$ ), salary welfare (beta $=0.219)$, the relationship between the colleague (beta $=0.216)$, see Table 4. Based on the above analysis results, the following regression equation can be obtained:

Overall satisfaction $(Y)=-0.162+0.155^{*}$ self-efficacy $(X 1)+0.174 *$ scientific research system $(X 2)+$ $0.205^{*}$ scientific research management $(X 3)+0.161 *$ salary welfare $(X 4)+0.160 *$ leadership factors $(X 5)$ $+0.178^{*}$ colleague relationship $(X 6)$ 
Table 4

Multiple linear regression analysis of influencing factors of overall satisfaction of researchers

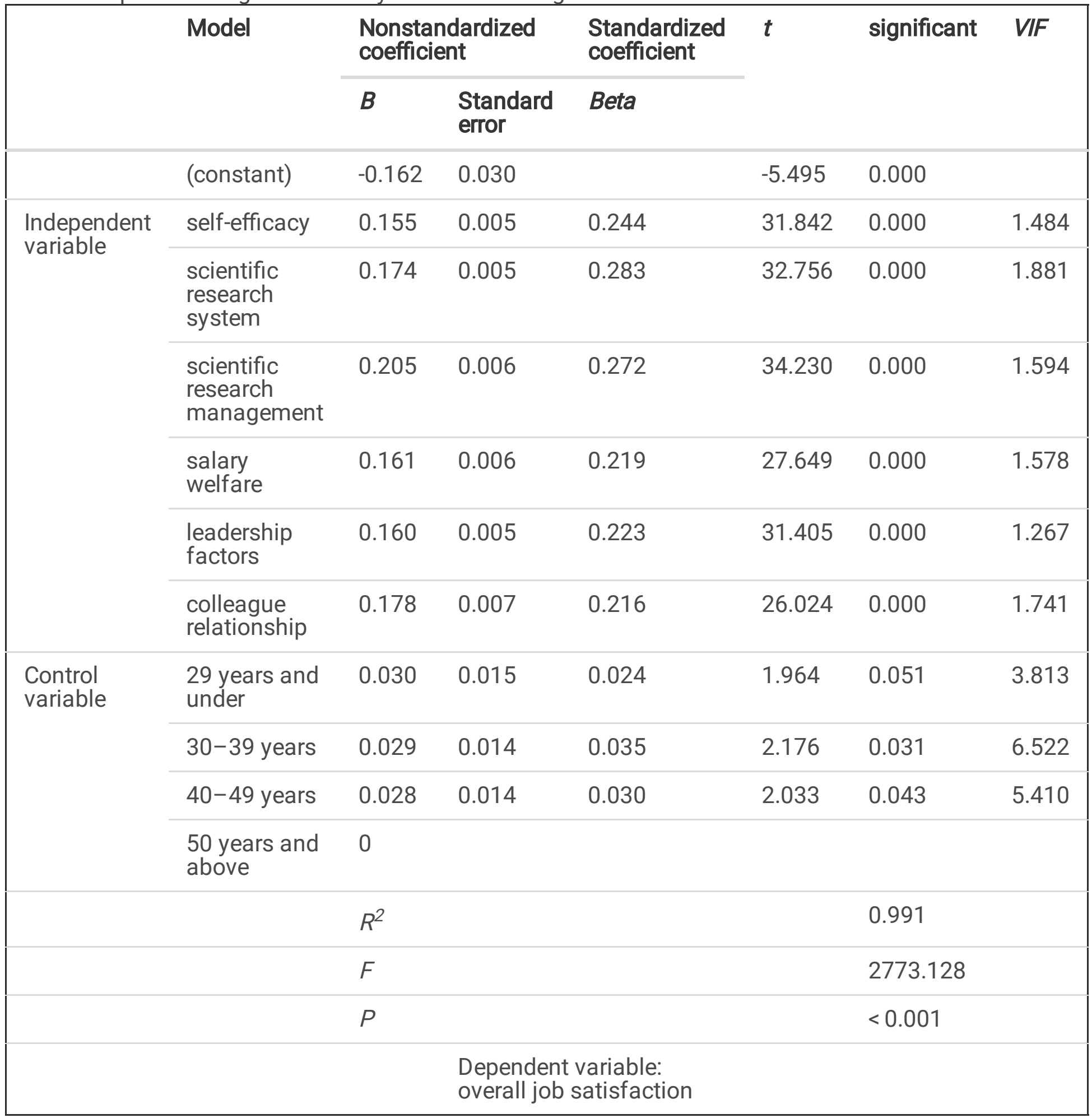

\section{Discussion}

\subsection{The work satisfaction of hospital researchers is at a satisfactory level}

According to the data analysis, the overall job satisfaction score of researchers in S Hospital is 3.64, which is between $3-4$, reaching the satisfaction level. Through factor analysis, it is found that the job 
satisfaction of researchers in S Hospital is composed of six dimensions: self-efficacy, scientific research system, scientific research management, salary and welfare, leadership factors and colleague relationship. The average score of satisfaction of the six dimensions is between 3.42 and 3.85, which indicates that the researchers in $\mathrm{S}$ hospital have a high job satisfaction.

\subsection{Analysis of influencing factors on job satisfaction of Hospital researchers}

The salary and welfare is one of the factors that affect the job satisfaction of hospital researchers. The Pearson correlation analysis shows that the correlation coefficient between salary and welfare and overall job satisfaction reaches 0.6 , which indicates that salary and welfare have a significant positive impact on overall job satisfaction. This is consistent with the results of Cabelkova I [17-20]et al. The difference analysis found that different ages, education, working years, professional titles and job categories all had statistically significant differences in salary and welfare satisfaction, and the above research results all indicated that salary and welfare had an impact on the job satisfaction of hospital researchers.

The results of data analysis show that compared with the five dimensions of self-efficacy and scientific research system, the satisfaction degree of salary and welfare is the lowest ( $3.42 \pm 0.57)$, and the difference analysis shows that the researchers with low education background, professional title and short working years have the lowest satisfaction on salary and welfare. According to Maslow's hierarchy of needs theory [21], salary and welfare are the necessary conditions to realize their basic needs. When the basic needs cannot be met, the satisfaction can not be improved, and the enthusiasm and efficiency of scientific research work are difficult to improve.

The scientific research system has the greatest influence on the hospital researchers' work satisfaction. The results of multiple linear regression analysis show that when six dimensions are taken as independent variables and overall job satisfaction is taken as dependent variables, the fitting degree reaches $99.1 \%$, which indicates that the explanatory power of each variable is very high and that each dimension has a certain degree of influence on overall satisfaction. According to the standardized coefficient, the research system has the greatest impact on the job satisfaction of researchers. Scientific research system mainly includes relevant systems of promotion, professional title evaluation and appointment, performance assessment and other aspects of hospital scientific research personnel, which is the "baton" of scientific research activities [22] and also the main way to identify the achievements of scientific research personnel. The data analysis found that the satisfaction of scientific researchers in $\mathrm{S}$ Hospital was $(3.68 \pm 0.82)$ in job promotion, $(3.70 \pm 0.72)$ in performance assessment, $(3.71 \pm 0.72)$ in title evaluation and recruitment, and $(3.70 \pm 0.68)$ in the overall scientific research system, indicating that the scientific researchers were satisfied with the scientific research system of the hospital.

The age of researchers has an impact on job satisfaction. The results showed that researchers aged $30-$ 39 and over 50 had the lowest overall job satisfaction, while those aged 40-49 had the highest overall job satisfaction, followed by those aged under 29. Combined with the difference analysis of the results, it is 
found that there are also differences in the satisfaction of researchers of different age groups on scientific research management, salary and benefits.

To be specific, researchers aged between 40 and 49 are basically at a stable stage in both family and work, have made certain achievements in the field of scientific research, and have a certain academic level and status. They have less pressure on scientific research, less pressure on life and work, and are more likely to have satisfaction and satisfaction in scientific research work冈Researchers aged 29 and under have just entered their jobs, and most of them are unmarried or married and have no children. They have little family pressure, and they are interested in exploring and seeking knowledge in medical scientific research. They also have more time and energy to engage in scientific research and are easily satisfied with scientific research work $\$ The reason for the low satisfaction of researchers in the age group of 30-39 is that most of them facing the promotion, the problem such as marriage, raising children, supporting the elderly[23], the situation has a certain restrictions on their scientific research work, make they don't have enough time and energy to understand the recent developments in related field, can't clear research direction, multiple pressure affects their scientific research job satisfaction[24]凶Over the age of 50 researchers continue to engage in scientific research is largely because the love for the scientific research work, the reason for their low satisfaction may be that they are limited by their age when applying for certain projects, but there are also some people who may be due to the decrease of their energy in scientific research as they grow older.

\subsection{Suggestions}

Improve the salary and welfare level of researchers. Material reward is not only one of the essential conditions to meet the physiological needs of researchers, but also a kind of affirmation to their scientific research work. Those engaged in medical scientific research are mainly highly educated talents with a master's degree or above, who tend to have a higher achievement orientation [25-26]. When their physical needs are satisfied, they pursue higher needs. Therefore, hospitals need to establish a more fair, just and reasonable salary and welfare system, establish a good incentive mechanism[27,28], and practically improve the treatment level of scientific researchers, so as to reduce their economic pressure and improve their enthusiasm for scientific research. In addition, we can also take spiritual incentive measures[29-30], such as hospital leaders care about and attach importance to scientific research personnel, and set up all kinds of inspiring scientific research honorary titles, so as to enhance the satisfaction and sense of achievement of scientific research personnel, so as to improve the efficiency of scientific research.

Change the concept of scientific research management, establish and improve the scientific research management system. Research [31] shows that there is a positive relationship between scientific research work satisfaction and scientific research performance. Scientific research work is a crucial link in the development of hospitals, and the work satisfaction of researchers affects the overall scientific research level of hospitals [6].In addition to completing heavy clinical work, researchers also need to invest a lot of time and energy to carry out scientific research[32]. Therefore, the hospital should change its concept in scientific research management, adhere to the principle of "people-oriented", emphasize the performance 
of scientific research, and pay attention to the needs of scientific researchers. Hospital leaders and policy makers need to make efforts to design and implement strategies that can alleviate the work pressure of researchers and balance their work and family life [33], so as to solve their worries, protect their rights and interests, continuously improve their work satisfaction, and ultimately promote the overall scientific research level of the hospital.

Targeted measures should be taken for researchers with low satisfaction. the satisfaction of researchers is jointly affected by their subjective consciousness and objective environment [5]. Therefore, hospital managers should take into account the differences between different groups when improving their satisfaction. For 30-39 scientific research personnel, the hospital can be understand by conducting seminars and other forms of difficulties and requirements of their current work, to take targeted measures to help them to solve difficulties, can also provide more learning resources and independent space for researchers by improving the hospital research platform, library system, updating laboratory equipment, setting up study rooms, etc, create a strong academic atmosphere, through the promotion of soft and hard conditions to improve their scientific research satisfaction[34].For researchers aged 50 and over, appropriate preferential policies should be adopted to apply for research projects according to their own abilities and needs. Seminars can also be held so that outstanding researchers with rich experience and outstanding scientific research achievements can impart experience, skills and solve doubts to young researchers, so as to improve the satisfaction of researchers and improve the overall scientific research level of the hospital.

\section{Conclusion}

Hospital researchers are a special group, and there are few researches on their job satisfaction. Through this survey, it is found that the job satisfaction of researchers is composed of and affected by multiple dimensions, among which the scientific research system has the most influence, and the improvement of salary and welfare level is a problem that must be solved in the process of continuously improving the satisfaction. In future studies, the scope can be expanded to focus on the job satisfaction of researchers at different levels of hospitals.

\section{Declarations}

\section{Acknowledgments}

This work was supported by the Non-profit central research Institute fund of Chinese academy of medical sciences 2019PT320003\ grant from the Department of talents of Guizhou Province, grants from Guizhou Science and Technology Cooperation Platform (2018-5801, 2018-5706)

\section{Author Contributions}

All the authors contributed to the design of the study and the critical appraisal of the findings. C.H.and N Ying $\mathrm{J}$ designed and supervised the project at all the stages of the study. N.Ying.J. conducted the 
systematic review. F.S.Y. and N.Yu.J. were fully engaged in the quantitative studies. C.H. and N.Ying.J. provided critical revision of the article. F.S.Y. was responsible for the integration of the previous findings. F.S.Y. and N.Yu.J. prepared the draft of the manuscript. All the authors read the draft and finally approved the article to be published. All the authors are accountable for the accuracy and integrity of the work.

\section{Data availability statement}

The datasets analysed during the current study are available from the corresponding author on reasonable request.

\section{Ethics approval and consent to participate}

Not applicable.

\section{Conflicts of Interest}

The authors declare no conflict of interest.

\section{References}

1. Guo Xiaochun, Shao Jing, Zhang Yanping,et al.(2017) Research on the construction of hospital scientific research management system by means of informatization.China health industry,Vol.14 No.36:174-175.

2. Ji Weiping, Pu Jiang, Wang Shengjun, et al.(2014) Research on hospital scientific research management based on employee satisfaction.Chin J Med Sci Res Manage,Vol.27 No.3:247248+252. 1

3. Zheng Wen-li,LIU Wei,BAO Xi-yan.(2011) An investigation on the source of stress and stress response of doctors in grade 3 a hospital.Chinese Journal of Rehabilitation,Vol.18 No.6:440-441.

4. Chen Shuying,HUANG Xiaoguang,Yu Yanping.(2017) Investigation and countermeasures of scientific research work for medical staff.Acta Universitatis Medicinalis Nanjing(Social Sciences),5:408-411.

5. Zhang Ying-yuan, Chen Zhuo, WANG Cheng-rong, et al.(2017) Research satisfaction survey and influence factor analysis of professional technicians in Beijing Maternity Hospital.Beijing Medical Journal,Vol.39 No.11:1169-1171. 2

6. Zhang Huifang, Miao Miao, Yu Lingling, et al.(2018) Satisfaction survey of scientific research incentive mechanisms in a grade A tertiary hospital. Chin J Med Sci Res Manage,Vol.31 No.2:123127. 3

7. Ren Ying, Zhou Chunlan, Chen Jie, et al.(2019) Correlation study on organizational innovation atmosphere and nurses' job satisfaction.Chin J Hosp Admin, Vol.35 No.3:231-234. 23

8. He Yuehui.(2016) Staff Satisfaction Survey of JST Hospital in Beijing.China University of Geosciences, Beijing. 
9. Hong Lu,Yang Zhao,Alison While.(2019) Job satisfaction among hospital nurses: A literature review.International Journal of Nursing Studies,94:21-31.

10. Yan Hanzhu.(2013) A Review of Job Satisfaction.Asian Social Science,Vol.9 No.1:293-298. 20

11. Saner,Latafat A,Gardashova,et al.(2016) Analysis of the Job Satisfaction Index Problem by Using Fuzzy Inference.Procedia Computer Science,102 $45-50.4$

12. WANG Hui,QIAN Yu,WANG Xiao-he,et al.(2017) Development and Validation Studies of Medical Staff Job Satisfaction Assessment Scale.Chinese Hospital Management,Vol.37 No.3:14-17. 5

13. Farrington SM,Lillah R.(2019) Servant leadership and job satisfaction within private healthcare practices. Leadersh Health Serv (Bradf Engl). Vol.32 No.1:148-168. 6

14. QIAO Man-jie,LV Hui-hui,WU Pan-pan.(2018) Analysis of Principal Component and Factor.Smart Healthcare,Vol.4 No.36:41-42. 6

15. Zhang Shiju,Liao Jianqiao.(2007) Research on the influence of various dimensions of employee job satisfaction on overall satisfaction.Science and management of science and technology,8:184-188. 7

16. S Kim,SM Park.Determinants of job satisfaction and turnover intentions of public employees:evidence from US federal agencies.International Review of Public Administration,Vol.19 No.1:63- 90.8

17. Cabelkova I,Abrham J,Strielkowski W: (2015) Factors influencing job satisfaction in post-transition economies: the case of the Czech Republic. Int J Occup Saf Ergon. Vol.21 No.4:448-56.

18. Yu X,Zheng M,Cheng X,et al.(2018) Job Satisfaction Among Doctors from Jiangsu Province in China. Med Sci Monit. Vol.8 No.24:7162-7169.

19. Du J,Xu X,Xiu L,et al.(2013) Analysis of job satisfaction of physicians from third-class general hospitals in Beijing with structural equation modeling study.J Zhengzhou University (Med Sci),Vol.48 No.2:228-232.

20. Kuburovic NB,Dedic V,Djuricic S,et al.(2016) Determinants of job satisfaction of healthcare professionals in public hospitals in Belgrade, Serbia-cross-sectional analysis. Srp Arh Celok Lek,Vol.144 No.3-4:165-173. 9-12

21. Chen Liming, Bian Lifang, Shao Lifang, et al.(2018) Status survey of job satisfaction of nurses at public hospitals and recommendations.Chin J Hosp Admin, Vol.34 No.6:500-504. 13

22. Tian Shumo, Zou Li-ai, JIANG Hong, et al.(2013) Analysis of the impacts of the level of scientific research and improvement strategies after the transformation of management system in a hospital,Guangzhou.Medicine and Society,Vol.26 No.12:42-44. 14

23. Pal S.(2012) A qualitative inquiry into work-family conflict among Indian doctors and nurses. Work,Vol.42 No.2:279-288.

24. Fu J,Sun W,Wang Y,et al.(2013) Improving job satisfaction of Chinese doctors:The positive effects of perceived organizational support and psychological capital.Public Health, Vol.127 No.10: 946-951. 15-16 
25. REN Feng, WANG Bo, ZHANG Baoyin, et al.(2010) An Empirical Study on Influencing Factors of Job Satisfaction of Science-Technology Workers with Different Education Background.Science and management of science and technology,Vol.31 No.1:149-152.

26. Yingchun Y,Jianqian C.(2008) A survey on job sat is fact ion of doctors in Nanjing.Chinese Hospital Management, VOL.28 No.3:31-33. 17-18

27. Wen $T$,Zhang $Y$,Wang $X$,Tang G.(2018) Factors influencing turnover intention among primary care doctors: A cross-sectional study in Chongqing, China.Hum Resour for Health, 16:10. 19

28. Meng R, Li J, Zhang Y, Yu Y, Luo Y, Liu X, Zhao Y, Hao Y, Hu Y, Yu C. Evaluation of Patient and Medical Staff Satisfaction regarding Healthcare Services in Wuhan Public Hospitals. Int J Environ Res Public Health. 2018 Apr 17;15(4):769. doi: 10.3390/ijerph15040769. PMID: 29673134; PMCID: PMC5923811.

29. Purohit B,Bandyopadhyay T.(2014) Beyond job security and money:driving factors of motivation for government doctors in India.Hum Resour Health,12:12.

30. Goetz K, Campbell SM, Broge B, et al. (2012) The impact of intrinsic and extrinsic factors on the job satisfaction of dentists.Community Dent Oral Epidemiol,Vol.40 No.5:474-480. 20-21

31. Gao Yan, WANG Mingxiao, ZHANG Wenjing, et al.(2011) Employee satisfaction survey and analysis in 13 general hospitals.Chin J Hosp Admin, Vol.27 No.10:745-747. 22

32. Li Shuo,Ding Shuzhen.(2013) Relationship between clinical research capacity and job satisfaction among nurses.Journal of Nursing Science,Vol.28 No.9:53-55.

33. Deng S,Yang N,Li S,et al.(2018) Doctors' Job Satisfaction and Its Relationships With Doctor-Patient Relationship and Work-Family Conflict in China: A Structural Equation Modeling. Inquiry,55:46958018790831. 24-25

34. Lu Y,Hu XM,Huang XL,et al. (2016) Job satisfaction and associated factors among healthcare staff: a cross-sectional study in Guangdong Province, China. BMJ Open, Vol.6 No.7:e011388. 